\title{
Anti-tumor properties of blackseed (Nigella sativa L.) extracts
}

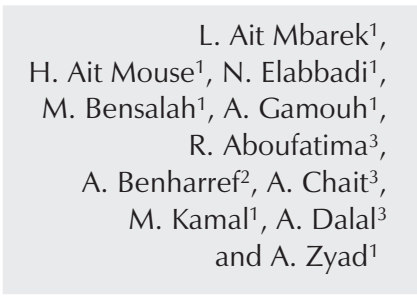

\author{
${ }^{1}$ Laboratory of Immunology, Biochemistry and Molecular Biology, \\ Faculty of Sciences and Technologies, Cadi-Ayyad University, Béni-Mellal, Morocco \\ ${ }^{2}$ Laboratory of Organic Chemistry and Heterocycles, Faculty of Sciences Semlalia, \\ Cadi-Ayyad University, Marrakech, Morocco \\ ${ }^{3}$ Laboratory of Ecophysiology, Faculty of Sciences Semlalia, Cadi-Ayyad University, \\ Marrakech, Morocco
}

\author{
Correspondence \\ A. Zyad \\ Laboratory of Immunology, \\ Biochemistry and Molecular Biology \\ Faculty of Sciences and Technologies \\ Cadi-Ayyad University \\ Box 523 \\ 23000 Béni-Mellal \\ Morocco \\ Fax: +00-212-2348-5201 \\ E-mail: ab.zyad@gmail.com
}

Research supported by the PROTARS III (D61/07), CNRST,

Morocco.

$\ldots \ldots \ldots \ldots \ldots \ldots \ldots$

Received July 18, 2005

Accepted February 23, 2007

....................

\begin{abstract}
The objective of the present study was to evaluate the in vitro and in vivo anti-cancer effect of Nigella sativa $\mathrm{L}$. seed extracts. The essential oil $\left(\mathrm{IC}_{50}=0.6 \%, \mathrm{v} / \mathrm{v}\right)$ and ethyl acetate $\left(\mathrm{IC}_{50}=0.75 \%\right)$ extracts were more cytotoxic against the $\mathrm{P} 815$ cell line than the butanol extract $\left(\mathrm{IC}_{50}\right.$ $=2 \%$ ). Similar results were obtained with the Vero cell line. Although all extracts had a comparable cytotoxic effect against the ICO1 cell line, with $\mathrm{IC}_{50}$ values ranging from 0.2 to $0.26 \%(\mathrm{v} / \mathrm{v})$, tests on the BSR cell line revealed a high cytotoxic effect of the ethyl acetate extract $\left(\mathrm{IC}_{50}=0.2 \%\right)$ compared to the essential oil $\left(\mathrm{IC}_{50}=1.2 \%\right)$. These data show that the cytotoxicity of each extract depends on the tumor cell type. In vivo, using the DBA2/P815 $\left(\mathrm{H}_{2}{ }^{\mathrm{d}}\right)$ mouse model, our results clearly showed that the injection of the essential oil into the tumor site significantly inhibited solid tumor development. Indeed, on the 30th day of treatment, the tumor volume of the control animals was $2.5 \pm 0.6 \mathrm{~cm}^{3}$, whereas the tumor volumes of the essential oil-treated animals were $0.22 \pm 0.1$ and $0.16 \pm 0.1 \mathrm{~cm}^{3}$ when the animals were injected with $30 \mu \mathrm{L}(28.5 \mathrm{mg}) /$ mouse and $50 \mu \mathrm{L}(47.5 \mathrm{mg}) /$ mouse per $48 \mathrm{~h}$ (six times), respectively. Interestingly, the administration of the essential oil into the tumor site inhibited the incidence of liver metastasis development and improved mouse survival.
\end{abstract}

Key words

- Nigella sativa L.

- Extracts

- Cytotoxicity

- Anti-tumor activity

\section{Introduction}

Plants are invaluable sources of new drugs. There is an enormous historical legacy regarding the use of plant preparations in folk medicine (1). Scientific studies on plants used in ethnomedicine have led to the discovery of many valuable drugs such as taxol, navelbine, camptothecin, vincristine, etc.
Nigella sativa L. (Ranunculaceae family) seeds, commonly known as blackseed or black cumin, have been employed for thousands of years as a spice and food preservative, as well as a protective and curative remedy for numerous disorders $(2,3)$. Traditionally, there is a common Islamic belief that blackseed is a panacea for all ailments, but cannot prevent aging or death. Blackseed 
is also identified as the curative black cumin in the Holy Bible and is described as Melanthion by Hippocrates and Dioscorides and as Gith by Pliny (4). Many studies have been conducted, particularly during the last two decades, on the effect of $N$. sativa L. seed extracts on various body systems in vitro or in vivo. The pharmacological investigations of the seed extracts reveal a broad spectrum of activities including immunopotentiation (5) and antihistaminic (6), antidiabetic (7), anti-hypertensive (8), anti-inflammatory (9), and antimicrobial activities (10). Many of these activities have been attributed to the quinone constituents of the seed $(11,12)$.

Furthermore, blackseed preparations may have a cancer chemopreventive potential and may reduce the toxicity of standard antineoplastic drugs (13). In fact, topical application of a blackseed extract inhibited the twostage initiation-promotion of skin carcinogenesis in mice by dimethylbenz[a]anthracene (croton oil) (13). In addition, others have reported an antitumor activity of some crude and purified components of $N$. sativa. In fact, Salomi et al. (14) have shown that a crude methanol extract of blackseed exhibited a strong cytotoxic action on Erlich ascites carcinoma, Dalton's ascites lymphoma and sarcoma 180 cells, with minimal cytotoxicity to normal lymphocytes. These investigators have also described the cytotoxic property of extracts of the seeds in vivo, as shown by inhibition of the growth of Erlich ascites carcinoma in mice receiving 2 $\mathrm{mg}$ of the extract per mouse per day for 10 days (14). Furthermore, a new triterpene saponin ( $\alpha$-hederin) recently isolated from blackseed showed significant dose-dependent tumor inhibition when given intraperitoneally for 7 days at 5 and $10 \mathrm{mg} / \mathrm{kg}$ to mice with formed tumors (15). Similarly, Worthen and colleagues (4) have tested in vitro a crude gum, a fixed oil and two purified components of the seed (thymoquinone (TQ) and dithymoquinone (DTQ)) for cytotoxicity to some parental and multidrug-resistant human tumor cell lines. They found that the gum and the oil (up to $1 \%, \mathrm{w} / \mathrm{v}$ ) were devoid of cytotoxicity, while both TQ and DTQ were cytotoxic to all cell lines including parental and multidrug-resistant phenotypeexpressing cells (14). In addition, other investigators have recently reported that TQ triggers apoptotic cell death in human colorectal cancer cells, which was correlated with G1 phase arrest of the cell cycle (16). Apoptosis induction by TQ was associated with an increase in mRNA expression of the p53 target gene, p21 ${ }^{\mathrm{WAF} 1}$, and a significant inhibition of the anti-apoptotic $\mathrm{Bcl}-2$ protein (16).

In the present study, we report comparative data regarding the in vitro cytotoxic effect of the essential oil and the ethyl acetate and butanol extracts of $N$. sativa seeds on a panel of tumor cell lines. We show that the essential oil and ethyl acetate fractions possess a strong cytotoxic effect against tumor cells. Furthermore, we present conclusive evidence that the in vivo effect of the essential oil when injected into the tumor site induced the regression of solid tumor volume and the inhibition of metastasis development and delayed mortality.

\section{Material and Methods}

\section{Chemicals, plant materials, cell lines, and} culture

$N$. sativa $\mathrm{L}$. seeds were purchased on the local market and authenticated by Pr. A. Ouyahia (Scientific Institute, Rabat, Morocco) and stored as a voucher specimen in the same institute. Adriamycin, dimethylsulfoxide (DMSO), crystal violet, butanol, ethyl acetate, and hexane were purchased from Sigma Chemical Co., Saint Quentin, France. The murine mastocytoma cell line (P815), the kidney carcinoma cell lines of monkeys (Vero) and hamsters (BSR) as well as the sheep heart carcinoma (ICO1) were kindly provided by Professor G. Lemaire, 
Institute of Biochemistry, University of Paris XI, France. These cell lines are routinely cultured in complete medium (Dulbecco's modified Eagle's medium supplemented with $5 \%$ fetal calf serum (Gibco BRL, Cergy Pontoise, France), $1 \%$ penicillin-streptomycin-neomycin, and $0.2 \%$ sodium bicarbonate (Sigma).

\section{Preparation of blackseed extracts}

Extraction of the essential oil. Steam distillation of the crushed blackseed removes the volatile oil content as an aqueous fraction from which the essential oil is isolated by simple extraction with diethyl ether followed by evaporation of the organic layer under reduced pressure. The essential oil content of $N$. sativa $\mathrm{L}$. was determined to be $0.4-0.5 \%(\mathrm{w} / \mathrm{w})$. This extract was analyzed by gas chromatography-mass spectrometry and revealed the presence of the following major components $(62.17 \% \mathrm{TQ}, 16.84 \%$ carvacrol, 8.29\% 2-methyl-5-Prop-2-enyldihydroquinone, $6.99 \%$ dihydrothymoquinone, $2.07 \%$ terpini-4-en-1-ol, $3.11 \%$ monoterpenes).

Preparation of ethyl-acetate and butanol extracts. One kilogram $N$. sativa L. seeds was washed, dried, and crushed to a powder with an electric micronizer. The powder was exhaustively extracted with $90 \%$ ethanol at room temperature and the extract was centrifuged at $10,000 \mathrm{~g}$ for $15 \mathrm{~min}$ to remove residual solid debris. The clear supernatant was then concentrated under reduced pressure.

The concentrated extract was partitioned between $10 \%$ methanol-water and n-hexane. After removing the n-hexane fraction, the aqueous layer was partitioned again with ethyl acetate, followed by n-butanol. The yields of the butanol and ethyl acetate extracts were 2.1 and $0.23 \%(\mathrm{w} / \mathrm{w})$, respectively. Analysis by nuclear magnetic resonance showed that the butanol extract contained two saponosides derived from $\alpha$-amyrin.
However, the ethyl acetate extract did not contain polyphenols and did contain monoxideterpenes.

\section{Methyl thiazole tetrazolium cell viability test}

The methyl thiazole tetrazolium (MTT) test was used to determine the effect of the essential oil and of the butanol and ethyl acetate extracts, all solubilized in DMSO, on the growth of non-adherent cells. The test was performed as described (17). Briefly, P815 cells were washed twice with PBS and incubated at a density of $7.5 \times 10^{4}$ cells $/ \mathrm{mL}$ in flat-bottomed 96-well microtiter plates (Bioster, Bastia di Rovolon, Italy) in $100 \mu \mathrm{L}$ of complete medium. Several dilutions starting from a concentration of $2 \%(\mathrm{v} / \mathrm{v})$ of these extracts in $100 \mu \mathrm{L}$ of complete medium were then added. After 48-h incubation in a humidified atmosphere at $37^{\circ} \mathrm{C}, 5 \% \mathrm{CO}_{2}, 100$ $\mu \mathrm{L}$ of medium was carefully removed from each well and replaced with $20 \mu \mathrm{L}$ MTT solution ( $5 \mathrm{mg} / \mathrm{mL}$ PBS). After 4-h incubation under the same conditions, the cleavage of MTT to formazan by metabolically active cells was quantified by scanning the plates at 540 and $630 \mathrm{~nm}$ using a multiscan apparatus. Three independent sets of experiments performed in duplicate were evaluated. Controls with DMSO alone were performed for each concentration. The growth inhibition rate was calculated as percentage of parallel negative controls. Adriamycin was used as positive control.

\section{Crystal violet test}

This test was performed as previously described $(18,19)$. Briefly, BSR, ICO1 and Vero cells were trypsinized and $7.5 \times 10^{4}$ cells per $\mathrm{mL}$ were incubated in flat-bottomed 96-well microtiter plates in $100 \mu \mathrm{L}$ of complete medium. Several dilutions starting from the concentration of $2 \%(\mathrm{v} / \mathrm{v})$ of these extracts were then added in a final volume of $100 \mu \mathrm{L}$ of complete medium. All extracts 
were solubilized in DMSO. Controls with DMSO alone were performed in parallel for each concentration. After 48-h incubation at $37^{\circ} \mathrm{C}$ and $5 \% \mathrm{CO}_{2}$, the medium was removed and replaced with $100 \mu \mathrm{L} 0.5 \%$ crystal violet solution. After 10-min incubation at room temperature, the plates were washed and viable crystal violet-stained cells were lysed with $1 \%$ SDS solution. Absorbance at 540 $\mathrm{nm}$ was then measured in each well. Adriamycin was used as positive control. The results of this test were also confirmed by the MTT test both qualitatively and quantitatively.

Using this colorimetric procedure, extract-mediated cell lysis and the cytotoxic effect of adriamycin (used as a positive control) were measured and compared to the viability of untreated cells according to the following calculation: $\%$ cell killing $=100 \mathrm{x}$ $\left(1-\mathrm{A} / \mathrm{A}_{\mathrm{O}}\right)$, where $\mathrm{A}_{\mathrm{O}}$ and $\mathrm{A}$ are the absorbances obtained from negative control cells and extract (or adriamycin)-treated cells, respectively.

The test compounds were compared using the $\mathrm{IC}_{50}$ value, i.e., the concentration of an individual compound leading to $50 \%$ death.

\section{Tumor induction in mice and treatment}

DBA2 mice $\left(\mathrm{H}_{2}{ }^{\mathrm{d}}\right.$ haplotype), purchased from the animal breeding center of Orleans (France), were maintained under specific pathogen-free conditions on a 12-h lightdark cycle. Mice were provided with sterile food and water ad libitum and were used at 6-8 weeks of age with an average weight of 20-25 g. All animal experiments were performed according to national regulations which are comparable to the accepted principles for laboratory animal use and care of the European Community guidelines.

A primitive tumor isograft was induced in mice after subcutaneous injection of $5 \mathrm{x}$ $10^{6}$ P815 cells $\left(\mathrm{H}_{2}{ }^{\mathrm{d}}\right)$. When the primitive tumor reached a palpable volume, the donor mouse was sacrificed, and the tumor was mechanically dissociated. Mice were then subcutaneously grafted with tumor fragments of similar size. Mouse treatment was started when a palpable grafted tumor had reached a volume of approximately $100 \mathrm{~mm}^{3}$. Three lots of 6 mice each were assigned to each treatment group. These mice were treated with PBS (group A) as negative control, or essential oil of $N$. sativa L. (30 $\mu \mathrm{L}(28.5$ $\mathrm{mg})$ per mouse for group B and $50 \mu \mathrm{L}(47.5$ $\mathrm{mg}$ ) per mouse for group $\mathrm{C}$ ). These quantities were injected into DBA2-tumor-bearing mice into the tumor itself at days $0,2,4,6,8$, and 10 (one injection every $48 \mathrm{~h}$, six times) (20). Thereafter, the tumor volume of each mouse was carefully measured with a calliper every 2 days for a period of 30 days according to the following calculation: tumor volume $\left(\mathrm{cm}^{3}\right)=\mathrm{Dx} \mathrm{d} / 2$, where " $\mathrm{D}$ " is the tumor length and "d" the tumor width (21). The weight of each mouse was also determined every 2 days for the same period of time.

\section{Metastasis evaluation}

To evaluate the effect of the essential oil of $N$. sativa L. on metastasis development, tumors were induced in DBA2 mice and treated using the protocol described above. After the 30th day, all surviving mice were sacrificed by cervical dislocation and submitted to autopsy. Autopsy was also performed on the animals that died before the 30th day. The incidence of liver metastasis was evaluated by counting the number of nodules in the liver of each mouse in all groups.

\section{Statistical analysis}

Data are reported as means \pm SD. Statistical differences between experimental groups were assessed by analysis of variance (ANOVA), with the level of significance set at $\mathrm{P}<0.05$. 


\section{Results}

In vitro cytotoxic effect of essential oil and the ethyl acetate and butanol extracts on different cell lines

The effect of essential oil and of the ethyl acetate and butanol extracts on different tumor cell lines is summarized in Table 1 . The table shows that the $N$. sativa $\mathrm{L}$. extracts have a differential cytotoxic activity on the various cell lines tested. The cytotoxic effect of the butanol extract was low on most of the cell lines tested, while the effect of the ethyl acetate and the essential oil extracts were variable, as indicated by the $\mathrm{IC}_{50}$ values. The essential oil and ethyl acetate extract were more cytotoxic than the butanol extract against the $\mathrm{P} 815$ cell line $\left(\mathrm{IC}_{50}(\% \mathrm{v} / \mathrm{v})=0.6\right.$, 0.75 , and $2 \%$, respectively). This classification of extracts in terms of cytotoxicity was also observed when the Vero cell line was used as target ( $\mathrm{IC}_{50}$ values: $0.2,0.22$, and $2 \%$ for the essential oil, ethyl acetate and butanol extracts, respectively). Interestingly, against the BSR cell line, the ethyl acetate extract was more cytotoxic than the essential oil ( $\mathrm{IC}_{50}: 0.2$ and $1.2 \%$, respectively), while the butanol extract showed a low cytotoxic activity. However, using the ICO1 cell line as target, the butanol extract exhibited a greater cytotoxic effect $\left(\mathrm{IC}_{50}=0.26 \%\right)$ than that observed against the P815 $\left(\mathrm{IC}_{50}=2 \%\right)$ and Vero $\left(\mathrm{IC}_{50}=2 \%\right)$ cell lines. Taken together, these results show that the cytotoxicity of each extract depends on the tumor cell type tested.

\section{Effect of the essential oil on solid tumor in mice}

Since the essential oil was the most cytotoxic extract against the P815 cell line, it was used to validate our in vitro observations in

\begin{tabular}{|c|c|c|c|c|}
\hline Cell lines & P815 & Vero & BSR & ICO1 \\
\hline \multicolumn{5}{|c|}{ Essential oil (\% v/v) } \\
\hline 1 & $78.26 \pm 6.50^{*}$ & $86.30 \pm 8.87^{*}$ & $45.23 \pm 3.80$ & $82.25 \pm 6.26^{*}$ \\
\hline 0.5 & $41.59 \pm 4.27$ & $83.46 \pm 8.14$ & $38.27 \pm 6.29$ & $72.92 \pm 6.96$ \\
\hline 0.25 & $35.41 \pm 5.53$ & $73.45 \pm 7.69$ & $17.72 \pm 4.48$ & $60.52 \pm 5.59$ \\
\hline 0.001 & $27.24 \pm 4.36$ & $21.61 \pm 2.06$ & $6.70 \pm 1.56$ & $29.39 \pm 3.21$ \\
\hline \multicolumn{5}{|c|}{ Ethyl acetate extract (\% v/v) } \\
\hline 0.5 & $39.09 \pm 4.71$ & $82.80 \pm 7.96^{*}$ & $83.75 \pm 7.66^{*}$ & $66.21 \pm 6.97^{*}$ \\
\hline 0.25 & $26.01 \pm 3.10$ & $73.46 \pm 6.69$ & $54.82 \pm 4.68$ & $57.07 \pm 4.22$ \\
\hline 0.001 & $9.93 \pm 2.58$ & $11.42 \pm 2.73$ & $11.59 \pm 3.20$ & $17.47 \pm 4.06$ \\
\hline \multicolumn{5}{|c|}{ Butanolic extract (\% v/v) } \\
\hline 1 & $22.88 \pm 4.00$ & $25.60 \pm 2.80$ & $26.53 \pm 4.61$ & $64.82 \pm 5.29^{*}$ \\
\hline 0.25 & $18.15 \pm 3.33$ & $1.23 \pm 0.70$ & $7.40 \pm 2.98$ & $44.03 \pm 4.73$ \\
\hline 0.001 & $2.07 \pm 0.32$ & $0.00 \pm 0.00$ & $0.00 \pm 0.00$ & $10.84 \pm 3.08$ \\
\hline \multicolumn{5}{|c|}{ Adriamycin $(\mu \mathrm{g} / \mathrm{mL})$} \\
\hline 40 & $86.20 \pm 7.50$ & $85.00 \pm 8.50$ & $66.48 \pm 5.93$ & $92.00 \pm 10.00$ \\
\hline 20 & $75.00 \pm 6.00$ & $64.00 \pm 8.20$ & $43.72 \pm 3.64$ & $78.00 \pm 6.50$ \\
\hline 5 & $10.00 \pm 1.50$ & $6.50 \pm 2.80$ & $4.44 \pm 1.63$ & $8.60 \pm 3.00$ \\
\hline
\end{tabular}

Cells $\left(7.5 \times 10^{4} / \mathrm{mL}\right)$ were treated with increasing concentrations of essential oil, ethyl acetate and butanol extracts. After 48-h incubation, cell lysis was determined as described in Material and Methods. Adriamycin was used as positive control. Data are reported as the mean \pm SD of three independent experiments. The values of cytotoxicity were compared with the lowest one obtained with the highest concentration of each extract against different cell lines ( ${ }^{*} \mathrm{P} \leq 0.05$, ANOVA). 
the DBA2/P815 $\left(\mathrm{H}_{2}{ }^{\mathrm{d}}\right)$ mouse model. Figure 1 shows that at day zero of treatment the tumor volume was about $0.35 \pm 0.06 \mathrm{~cm}^{3}$ for all groups tested $(\mathrm{P}>0.05)$. The in situ administration of the essential oil significantly reduced solid tumor development in

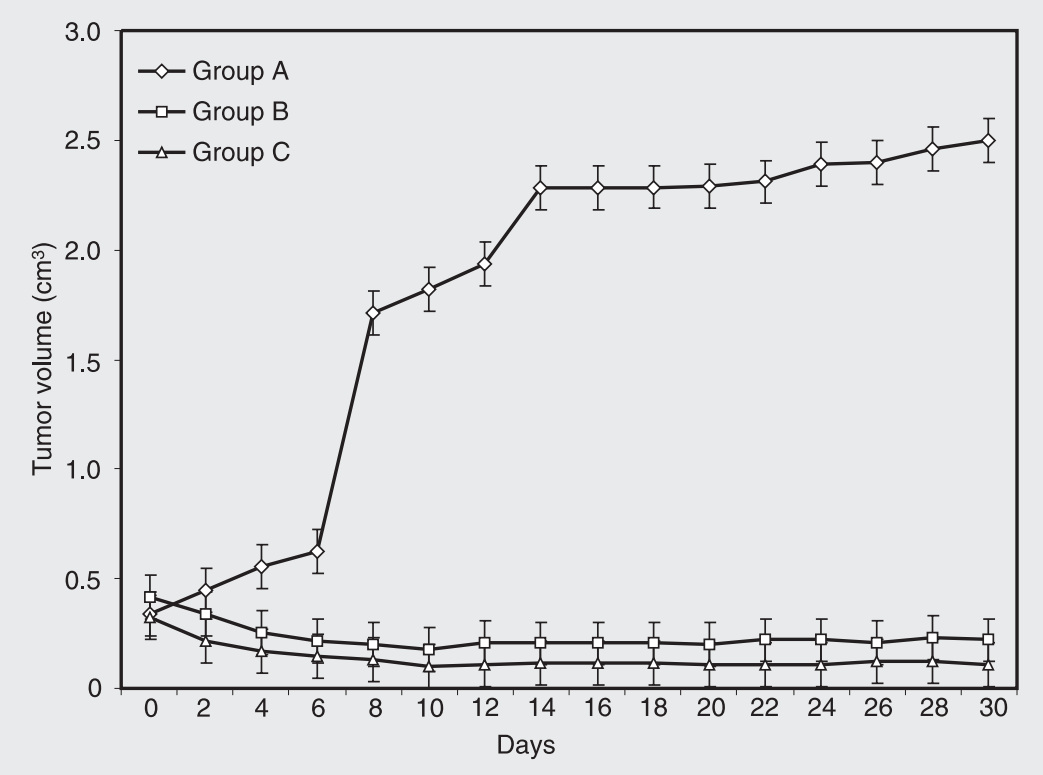

Figure 1. Effect of Nigella sativa essential oil on tumor volume evolution in mice. Tumors were induced in DBA2 mice and treated using the protocol described in Material and Methods. Three groups of 6 mice each including controls were used. These groups were treated with PBS as negative control (group A) or essential oil of $N$. sativa L. ( $30 \mu \mathrm{L}(28.5$ $\mathrm{mg}$ ) or $50 \mu \mathrm{L}(47.5 \mathrm{mg})$ per mouse for groups B and C, respectively). After serial injections of essential oil into the tumor itself at days $0,2,4,6,8$, and 10, tumor volume was carefully measured with a calliper in each mouse every two days as described in Material and Methods. Data are reported as the mean $\pm S D$ of three independent experiments. $P \leq 0.05$ compared to group A (negative control) for all times from 6 to 30 days (ANOVA).

Table 2. Effect of essential oil on survival and metastasis development in tumorbearing mice.

\begin{tabular}{lcr}
\hline Mouse group & Nodule number per mouse & Mortality (\%) \\
\hline Group A (untreated) & $14 \pm 3$ & $83 \pm 4$ \\
Group B (30 $\mu \mathrm{L} ; 28.5 \mathrm{mg} /$ mouse) & $2 \pm 1$ & $16.6 \pm 2$ \\
Group C (50 $\mathrm{LL} ; 47.5 \mathrm{mg} /$ mouse) & 0 & 0
\end{tabular}

Tumors were induced in DBA2 mice and treated using the protocol described in Material and Methods. During the experiments, all mice that died before the 30th day of study were submitted to autopsy and the number of liver metastases was evaluated. On the 30th day of the study, surviving mice were sacrificed and autopsied and the incidence of liver metastases was evaluated. The number of nodules (metastases) in each mouse and the mortality rate are reported as the mean $\pm S D$ of three different experiments. The results were statistically significant $(P<0.05$, ANOVA) when groups $\mathrm{B}$ and $\mathrm{C}$ were compared to group $\mathrm{A}$ and also when group $\mathrm{B}$ was compared to group $\mathrm{C}$. the treated groups compared to the PBStreated control $(\mathrm{P}<0.05)$. On the 30th day, the tumor volume of the control animals was $2.5 \mathrm{~cm}^{3}$ (group A), whereas that of the treated animals were $0.22 \pm 0.1$ and $0.16 \pm 0.1 \mathrm{~cm}^{3}$ for groups $\mathrm{B}$ and $\mathrm{C}$, respectively. This difference was found to be significant between the control and treated groups $(\mathrm{P}<0.05)$. However, no significant difference was observed between the treated groups (B and C) on day 30. It is noteworthy that the tumor volume decreased between day " 0 " and day 12 for the treated groups (B and C). This difference was significant $(\mathrm{P}<0.05)$ at day 12 , suggesting a cytotoxic activity of the extract. These tumor volumes remained constant between the 12th and 30th days, suggesting an inhibition of cell growth during this period.

\section{Effect of essential oil on metastasis development and mouse survival}

To determine whether the observed antitumor activity of the $N$. sativa essential oil was correlated with the anti-metastatic effect, tumor-bearing mice were sacrificed and autopsied for the evaluation of the incidence of liver metastasis. A comparative study between the three groups (Table 2) showed that on the 30th day of treatment, the number of nodules in the control animals (group A) was $14 \pm 3$, whereas in the treated animals (groups B and C) it was $2 \pm 1$ and 0, respectively. These results demonstrate either that the essential oil has an anti-metastatic activity in mice or that it inhibits or delays metastasis by rapid reduction of primary tumor volume at the site of induction.

In order to establish the relationship between the in vivo cytotoxic activity of the essential oil and mouse survival, the death rate was determined for each group of tumor-bearing mice (Table 2). No mortality was observed in group $\mathrm{C}$ on the 30th day of treatment. However, on the same day, 83 and $16.6 \%$ mortality rates were noted for 
groups $\mathrm{A}$ and $\mathrm{B}$, respectively, indicating that the essential oil can reduce tumor-bearing mice mortality in a dose-dependent manner.

\section{Discussion}

The present study was undertaken to provide comparative data on the in vitro cytotoxic activity of different extracts of $\mathrm{N}$. sativa $\mathrm{L}$. seeds against various tumor cell lines. The ethyl acetate and essential oil fractions exhibited a significant cytotoxic effect against the majority of tumor cell lines used, while the butanol extract showed only little cytotoxic activity. Interestingly, we report here that the differential cytotoxic effect of these extracts was related not only to their chemical composition but also to the nature of the tumor cell lines. In fact, although all the extracts studied showed a comparable cytotoxic effect against the ICO1 cell line, the effect of the essential oil was higher against the P815 cell line as compared to that of the ethyl acetate, which was more cytotoxic against the BSR cell line than the essential oil. Our results agree with previous research in which the ethyl acetate fraction was found to exhibit a strong growth inhibitory effect on all malignant cells tested (22). The differential cytotoxicity of these extracts against the same cell line is related to the differential composition of such extracts. These observations agree with previous study (4) in which the crude gum, the fixed oil and two purified components of the essential oil (TQ and DTQ) were tested for in vitro cytotoxicity to some parental and multidrugresistant human tumor cell lines. It was found that the gum and fixed oil were devoid of a cytotoxic effect. However, TQ and DTQ, the major constituents of the essential oil, were both cytotoxic to all cell lines and their action was not related to the generation of free radicals (4). Furthermore, the presence of terpenes as major components in the ethyl acetate extract may explain its high cytotoxic activity. In fact, the anti-cancer poten- tial of these products has been recently reported (23-26). The molecular mechanisms of these purified components have not been well characterized. However, it has been recently reported that TQ triggers apoptotic cell death in human colorectal cancer cells which was correlated with G1 phase arrest of the cell cycle (16). Apoptosis induction by TQ was associated with an increase in mRNA expression of the p53 target gene, $\mathrm{p} 21^{\mathrm{WAF} 1}$, and a significant inhibition of anti-apoptotic Bcl-2 protein (16).

On the other hand, to evaluate the side effects of these extracts, we tested their cytotoxicity toward normal human peripheral blood mononuclear cells. Interestingly, only minimal cytotoxicity was observed for all extracts (data not shown).

Since the essential oil was the extract with the highest in vitro cytotoxic activity against P815 cell line compared to the ethyl acetate and butanol extracts, it was used to validate this observation in the DBA2/P815 $\left(\mathrm{H}_{2}{ }^{\mathrm{d}}\right)$ mouse model. When we injected the essential oil into the tumor site of tumorbearing mice a very clear regression curve was observed for tumor volume in relation to time in the treated groups, while the control group exhibited an increasing tumor volume (Figure 1). These results are consistent with previous findings that demonstrated the in vivo cytotoxic property of the seeds by inhibiting the growth of Erlich ascites carcinoma in mice receiving $2 \mathrm{mg}$ of the methanol extract per mouse per day for 10 days (14). They also agree with those of Badary's group (27), which reported an inhibitory effect of the main component of the essential oil (TQ) against 20-methylchloranthrene-induced fibrosarcoma and against benzo (a) pyrene-induced forestomach carcinogenesis (28).

In the present study, the regression of tumor volume was more pronounced in the treated mice (up to 95\% for group C; Figure 1 ), suggesting that other components present in the essential oil contribute to the ob- 
served in vivo regression of established malignancy. Furthermore, the incidence of mortality in tumor-bearing mice was delayed by essential oil treatment, with no mortality for group C and only $16.6 \pm 2 \%$ mortality for group B as compared to $83 \pm$ $4 \%$ for group A (PBS-treated group) at day 30 of the study (Table 2). It is noteworthy that the body weight of treated mice remained stable in group C (data not shown).

Our results indicate for the first time that intra-tumor treatment of tumor-bearing mice with essential oil may have led to the inhibition of metastasis development (Table 2). These results demonstrate either that the essential oil has an anti-metastatic activity in mice or that it inhibits or delays metastasis by rapid reduction of primary tumor volume at the site of induction. The active principles and their metastasis-inhibiting mechanism still need to be identified.

The present study demonstrates that the cytotoxic activity of blackseed extracts is a complex phenomenon depending not only on the nature of the extract and its components, but also on the tumor cell type. We report here a very high efficacy of the essential oil in reducing tumor volume, inhibiting metastasis development and delaying mortality of P815 tumor-bearing mice. Additional research is now necessary in order to determine the agents responsible for these in vitro and in vivo anti-cancer activities as well as the molecular mechanisms involved in their effects.

\section{Acknowledgments}

The authors thank Prof. Z. Brahmi (Riley Children's Hospital, Indianapolis, IN, USA), Dr. J. Couderc (Institut Paris Sud, Clamart, France) and Prof. A. El Meziane (FSTGuéliz, Marrakech, Morocco) for reviewing the manuscript.

\section{References}

1. Suffness M, Douros J. Methods in drugs development. De Vita Jr and Busch $\mathrm{H}$ (Editors), Drugs of plant origin. New York: Academic Press; 1982.

2. Chopra RN, Nayar SL, Chopra IC. Glossary of Indian medicinal plants. New Delhi: Council of Scientific and Industrial Research; 1956.

3. Nadkarni K. Crocus sativus, Nigella sativa. In: Nadkarni KM (Editor), Indian materia medica. Bombay: Popular Prakashan; 1976. p 386411.

4. Worthen DR, Ghosheh OA, Crooks PA. The in vitro anti-tumor activity of some crude and purified components of blackseed, Nigella sativa L. Anticancer Res 1998; 18: 1527-1532.

5. Medinica R, Mukerjee S, Huschart T, Corbitt W. Immunomodulatory and anticancer activity of Nigella sativa plant extract in humans. Proceedings of the American Association for Cancer Research Annual Meeting. 1994. p A2865.

6. Mahfouz M, Abdel-maguid R, El-Dakhakhny M. The effect of nigellon therapy on the histaminopexic power of blood sera asthmatic patients. Arzneimittelforschung 1965; 15: 1230-1231.

7. Al-Hader A, Aqel M, Hassan Z. Hypoglycaemic effects of the volatile oil of Nigella sativa. Int J Pharmacognosy 1993; 31: 96-100.

8. El Tahir KE, Ashour MM, al-Harbi MM. The cardiovascular actions of the volatile oil of the black seed (Nigella sativa) in rats: elucidation of the mechanism of action. Gen Pharmacol 1993; 24: 1123-1131.

9. Houghton PJ, Zarka R, de las Heras B, Hoult JR. Fixed oil of Nigella sativa and derived thymoquinone inhibit eicosanoid generation in leukocytes and membrane lipid peroxidation. Planta Med 1995; 61: 33-36.

10. El-Alfy $\mathrm{T}, \mathrm{El}$-Fatatry $\mathrm{H}$, Toama $\mathrm{M}$. Isolation and structure assignment of an anti-microbial principle from the volatile oil Nigella sativa $\mathrm{L}$. Pharmazia 1975; 30: 109-111.

11. Mahfouz M, El-Dakhakhny M. The isolation of a crystalline active principle from Nigella sativa seeds. Pharm Sci United Arab Rep 1960; 1: 19.

12. Ali BH, Blunden G. Pharmacological and toxicological properties of Nigella sativa. Phytother Res 2003; 17: 299-305.

13. Salomi NJ, Nair SC, Jayawardhanan KK, Varghese CD, Panikkar KR. Antitumour principles from Nigella sativa seeds. Cancer Lett 1992; 63: 41-46.

14. Salomi MJ, Nair SC, Panikkar KR. Inhibitory effects of Nigella sativa and saffron (Crocus sativus) on chemical carcinogenesis in mice. Nutr Cancer 1991; 16: 67-72.

15. Swamy SMK, Tan BKH. Extraction, isolation and characterization of anti-tumor principle, alpha-Hederin, from the seeds of Nigella sativa. Planta Medica 2001; 67: 29-32.

16. Gali-Muhtasib H, Diab-Assaf M, Boltze C, Al-Hmaira J, Hartig R, Roessner $\mathrm{A}$, et al. Thymoquinone extracted from black seed triggers apoptotic cell death in human colorectal cancer cells via a p53dependent mechanism. Int J Oncol 2004; 25: 857-866.

17. Mosmann T. Rapid colorimetric assay for cellular growth and sur- 
vival: application to proliferation and cytotoxicity assays. J Immunol Methods 1983; 65: 55-63.

18. Zyad A, Branellec D, Mahe Y, Tursz T, Chouaib S. The development of human tumor-cell resistance to TNF-alpha does not confer resistance to cytokine-induced cellular cytotoxic mechanisms. Int J Cancer 1992; 52: 953-958.

19. Zyad A, Benard J, Tursz T, Clarke R, Chouaib S. Resistance to TNF-alpha and adriamycin in the human breast cancer MCF-7 cell line: relationship to MDR1, MnSOD, and TNF gene expression. Cancer Res 1994; 54: 825-831.

20. Zyad A, Cai Z, Morizet J, Legres LG, Benard J, Chouaib S. In vivo effect of the combination of TNF and adriamycin against a human breast cell line expressing the MDR-phenotype. Int J Oncol 1995; 7: 1067.

21. Yoshikawa T, Kokura S, Tainaka K, Naito Y, Kondo M. A novel cancer therapy based on oxygen radicals. Cancer Res 1995; 55: 1617-1620.

22. Swamy SM, Tan BK. Cytotoxic and immunopotentiating effects of ethanolic extract of Nigella sativa L. seeds. J Ethnopharmacol 2000; 70: 1-7.
23. Mizushina Y, lida A, Ohta K, Sugawara F, Sakaguchi K. Novel triterpenoids inhibit both DNA polymerase and DNA topoisomerase. Biochem J 2000; 350 (Part 3): 757-763.

24. Zhang S, Won YK, Ong CN, Shen HM. Anti-cancer potential of sesquiterpene lactones: bioactivity and molecular mechanisms. Curr Med Chem Anticancer Agents 2005; 5: 239-249.

25. Rafi MM, Bai NS, Chi TH, Rosen RT, White E, Perez D, et al. A sesquiterpenelactone from Inula britannica induces anti-tumor effects dependent on Bcl-2 phosphorylation. Anticancer Res 2005; 25 : 313-318.

26. Fukuyama Y, Minoshima Y, Kishimoto Y, Chen IS, Takahashi H, Esumi T. Iridoid glucosides and p-coumaroyl iridoids from Viburnum Iuzonicum and their cytotoxicity. J Nat Prod 2004; 67: 1833-1838.

27. Badary OA, Gamal EI-Din AM. Inhibitory effects of thymoquinone against 20-methylcholanthrene-induced fibrosarcoma tumorigenesis. Cancer Detect Prev 2001; 25: 362-368.

28. Badary OA. Thymoquinone attenuates ifosfamide-induced Fanconi syndrome in rats and enhances its antitumor activity in mice. $J$ Ethnopharmacol 1999; 67: 135-142. 